\title{
Rectal Leiomyoma with Fibromuscular Obliteration Mimicking Adematous Lesion
}

H. Nakase ${ }^{1}$, M. Ide ${ }^{2}$, S. Yazumi ${ }^{1}$, N. Watanabe ${ }^{1}$, T. Itoh ${ }^{1}$, M. Matsuura ${ }^{1}$, C. Kawanami ${ }^{1}$, K. Okazaki ${ }^{1}$, T. Chiba ${ }^{1}$ ${ }^{1}$ Division of Gastroenterology and Endoscopic Medicine, Graduate School of Medicine, Kyoto University, Kyoto, Japan

${ }^{2}$ Nishiki Clinic, Sasayama, Hyogo, Japan

Corresponding Author

K. Okazaki, M.D., Ph.D.

Division of Gastroenterology and Endoscopic Medicine Graduate School of Medicine Kyoto University

54 Shogoinkawara-cho

Sakyoku, Kyoto, 606-8507

Japan

Fax: $\quad+81-75-7514303$

E-mail: okak@kuhp.kyoto-u.ac.jp

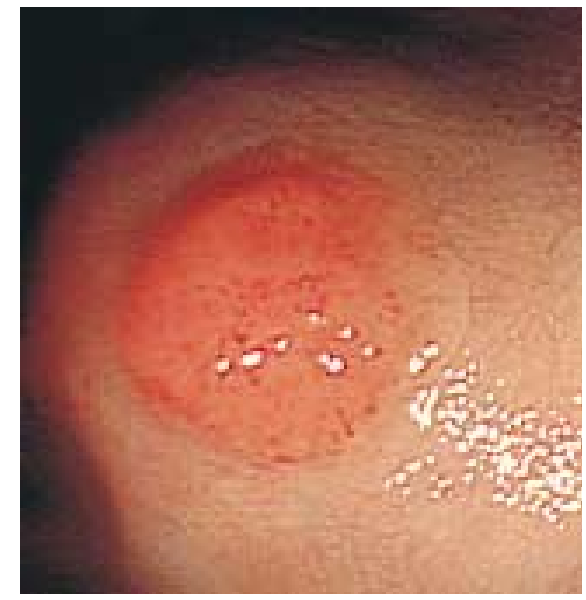

Figure 1 A 54-year-old man with a main complaint of hematochezia underwent colonoscopic examination, which revealed a sessile elevated lesion with reddish mucosa on the surface at the rectum. Endoscopic mucosal resection was done without complications

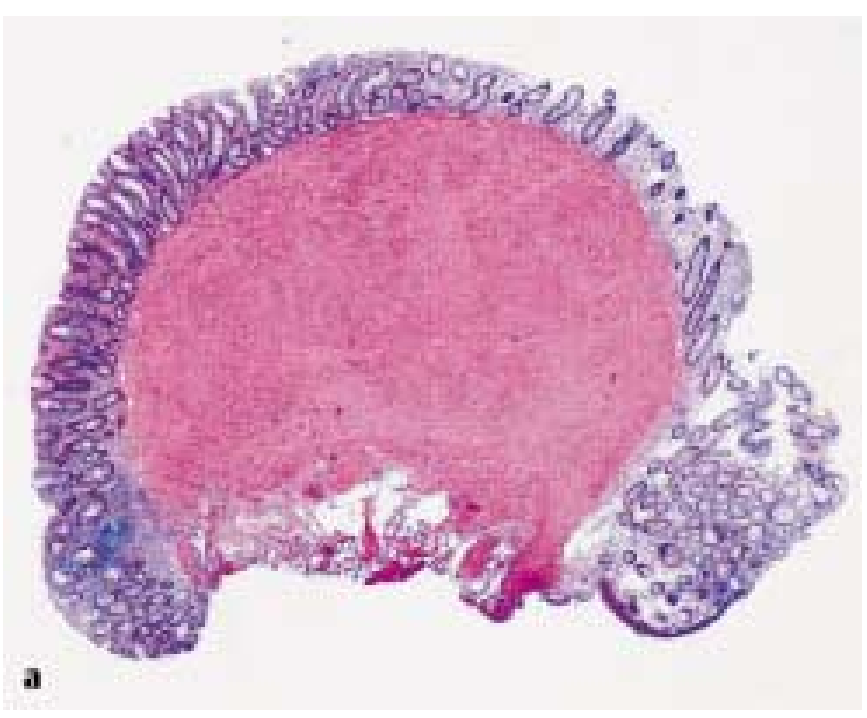

Figure 2 Histological examination showed this tumor to be mainly composed of leiomyocytes in the submucosa $(\mathbf{a}, \times 20)$, with fibromuscular obliteration in the lamina propria (b, $\times 200)$. We speculate that mucosal prolapse by evacuation might result in epithelial change on the surface of rectal leiomyoma

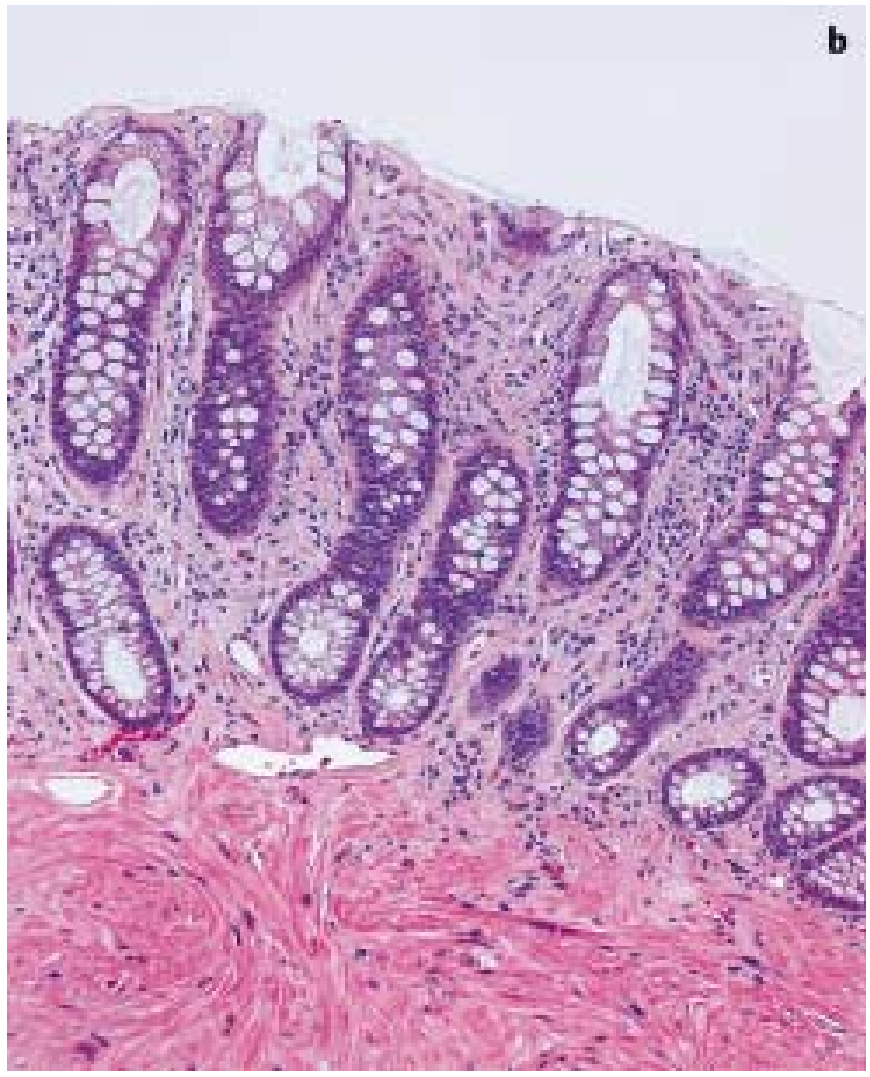

